\title{
NYUDKOMMEN LITTERATUR.
}

De nordiska kriminalistföreningarnas årsbok 1951-52. Stockholm 1953. 368 sider.

Haefliger, Arthur: Der Begriff der Urkunde im schweizerischen Strafrecht. Verlag für Recht und Gesellschaft. Basel 1952. 76 sider.

Handbook on the Inmate's Relationships with Persons From Outside the Adult Correctional Institution. Prepared by the Committee on Classification and Casework. The American Prison Association. New York 1953. 74 sider.

Internationaler Juristen-Kongress Westberlin 1952. Gesamtbericht. Herausgegeben vom Internationalen Juristen-Ausschuss. Berlin 1953. 171 sider.

International Penal and Penitentiary Foundation. Proceedings of the sessions held at Brussels (December 1951) and Geneva (December 1952). Melun (France) 1953. 61 sider.

L'examen médico-psychologique et social des délinquants. Conférences publiées par Georges Heuyer et Jean Pinatel. Premier Cours International de Criminologie. Paris 1953. 684 sider.

Martienssen, Anthony: Crime and the Police. Penguin Books. Melbourne-London-Baltimore. 256 sider. 2/- sh.

Neustatter, W. Lindesay: Psychological Disorder and Crime. Christopher Johnson. London 1953. 248 sider, 21 sh.

Notable British Trials Series. Vol. 78. Trial of John George Haigh (The Acid Bath Murder). Edited by Lord Dunboyne. William Hodge \& Co. London 1953. 271 sider. 15/- sh.

Partridge, Ralph: Broadmoor. A History of Criminal Lunacy and its Problems. Chatto \& Windus. London 1953. 278 sider. 21 sh.

Thompson, George N.: The Psychopathic Delinquent and Criminal. Charles C. Thomas. Springfield, Illinois, U.S.A. 1953. 157 sider.

Unrecht als System. Dokumente über planmässige Rechtsverletzungen im sowjetischen Besatzungsgebiet. Herausgegeben vom Bundesministerium für gesamtdeutsche Fragen. Berlin 1953. 239 sider. 